\title{
TRABALHADORES, SINDICALISMO E POLÍTICA: 1978, QUARENTA ANOS DEPOIS
}

Este ano, ao redor do mundo, estão sendo organizadas atividades comemorativas dos cinquenta anos das mobilizações e protestos que tiveram lugar no ano de 1968. Ainda que na história e memória tenha ficado a forte marca do "maio francês", 1968 globalizou-se apesar das diferenças, desarticulação e multiplicidades. Com centralidade nos movimentos estudantis, essa onda teve suporte também, entre outros, das classes trabalhadoras em diversos países. No Brasil, não será diferente. Muitos eventos estão sendo realizados com vistas a recuperar e debater os acontecimentos desse ano fulgurante (Santana, 2018).

Em meio a isso, muitos eventos importantes para a história nacional correm o risco de ficar esmaecidos diante da pujança de 1968. Nesse sentido, tratar do ciclo de contestação aberto com a greve dos metalúrgicos do ABC Paulista de 1978 - quando ele completa quarenta anos - tem grande valia. Seja pelo evento em si e sua importância histórica, seja por quando o colocamos em diálogo direto com o momento atual, marcado por um novo cenário global de recuada das forças sociais do trabalho mediante os avanços das políticas regressivas para o mundo do trabalho. Refletir sobre aquele ciclo em relação ao presente, a um só tempo, pode tanto lançar luz sobre aquela conjuntura quanto sobre os processos em curso, tendo em vista seus atores sociais e a dinâmica de sua interação (Santana, 2015; Rodrigues, Lima e Ramalho, 2018).

Em 12 de maio de 1978, com a greve iniciada na fábrica da Scania, em São Bernardo do Campo, o Brasil assistiu a uma onda de greves sem precedentes nestes últimos quarenta anos que se passaram desde o início da eclosão grevista do final dos anos 1970. 
O ano de 1978 representou um momento importante para a luta dos trabalhadores em nosso país. Dez anos havia se passado do movimento grevista de Contagem e Osasco, que representou o nosso 1968 operário. Naquele momento, as greves, nessas duas cidades, significaram um protesto das classes trabalhadoras e, em particular, dos metalúrgicos contra as condições de trabalho, bem como uma reação à ditadura militar então vigente.

A "explosão" grevista iniciada em 1978, seja pela abrangência, pelo momento político que o Brasil estava vivendo, ou pelos atores que estavam adentrando, com as greves, a cena pública, deixou marcas significativas e duradouras no mundo do trabalho e no sindicalismo, em particular, e na sociedade brasileira, em geral. Os experimentos organizativos e mobilizatórios então efetivados deitaram raízes, vindo a se tornar posteriormente o projeto político e sindical hegemônico no campo das esquerdas de nosso país (Rodrigues, 1999).

De certa forma, pode-se dizer que setores da sociedade civil foram surpreendidos por esse movimento. Trabalhadores/as com sua mobilização passam a ser contados, de forma inescapável, em termos dos arranjos políticos, que se pretendiam efetivar sem a presença e participação deles, mas também da vida pública nacional de forma mais ampla. Desde então tornou-se frequente e notável a presença deles/as nas grandes mídias, das pequenas e esparsas menções, assumiram certa centralidade no noticiário político do país.

Não resta dúvida de que o ciclo em questão trouxe para o centro do debate social e político nacional toda uma agenda na qual tinham centralidade as demandas de trabalhadores e trabalhadoras, situando de forma efetiva a questão dos direitos para amplos setores da classe trabalhadora.

Será exatamente a força e dimensão assumida pelo movimento dos trabalhadores que - a exemplo da África do Sul e Coréia do Sul - retardará um conjunto de mudanças pelas quais passava o mundo do trabalho dos países do capitalismo 
central, de efeitos bastante deletérios para a vida, o trabalho e a organização dos/as trabalhadores/as. Pode-se dizer que esses processos foram postergados por uma década, dada a ação efetiva da classe trabalhadora brasileira e de seus sindicatos. Enquanto as forças sociais do trabalho - em várias partes do mundo - amargavam duros reveses e recuos, a classe trabalhadora brasileira dava sinais de vitalidade em termos de organização e mobilização (Rodrigues, 2011).

Isso fica patente, também, no processo que vem nessa mesma esteira, em termos de construção de organizações nacionais, políticas e sindicais. Muito rapidamente, no bojo desse ciclo, trabalhadores e trabalhadoras construirão pelo menos duas centrais sindicais cobrindo todo o país, bem como um partido de marcada extração operária e sindical, que, com menos de uma década de existência - mas então ancorado na ascensão dos movimentos sindical e popular se credencia para, em uma eleição presidencial, já se colocar como uma possível alternativa de poder que vinha das ruas, mas também da longa marcha de consolidação institucional.

Este dossiê temático, 40 anos das greves de 1978 e os dilemas do sindicalismo na atualidade, levando em conta as questões suscitadas anteriormente, tem como objetivo problematizar esse período e refletir, de um lado, sobre as consequências trazidas pela explosão grevista do período 1978-1980 e, de outro, analisar as várias facetas desse processo e os desafios à ação sindical nos dias de hoje, tanto nacional como internacionalmente (ver Gumbrell-McCormick e Hyman, 2013).

No que diz respeito aos artigos que o compõem, temos o seguinte: em "Trabalhadores, confronto político e democracia: o ciclo de greves do ABC paulista e os desafios do sindicalismo atual", Marco Aurélio Santana analisa a greve dos metalúrgicos no ABC paulista no período 1978-1980 e argumenta que esse movimento significou um ciclo de greves e contestação que se manteve nos anos 1980 e 1990. O texto versa sobre a forma como os metalúrgicos participaram 
desse processo analisando seus limites e possibilidades e, a partir das questões que estavam postas naquele período, discute os principais desafios vividos na atualidade pelo mundo do trabalho e o sindicalismo brasileiro.

José Ricardo Ramalho e Iram Jácome Rodrigues, no artigo "Sindicalismo do ABC e a era Lula: contradições e resistências", chamam atenção para o fato de que o sindicalismo metalúrgico do $\mathrm{ABC}$, em sua trajetória no enfrentamento político e nas greves no período da ditadura militar de 1964, criou condições para defender suas demandas econômicas na esfera pública, ao mesmo tempo que se constituiu em uma força política no cenário nacional. Nesse sentido, a eleição de Luiz Inácio Lula da Silva à Presidência da República, em 2002, representou a força política desse sindicalismo que estabeleceu novos parâmetros e influenciou os rumos da organização dos trabalhadores no país. O objetivo do texto é estabelecer uma relação, a partir de levantamento de dados estatísticos sobre trabalho e emprego na região do ABC Paulista, entre o contexto econômico do período Lula/Dilma e a estratégia sindical dos metalúrgicos.

Roberto Véras de Oliveira e Mario Henrique Guedes Ladosky, no artigo "Das greves do ABC ao Conselho de Relações de Trabalho: chances e limites da ação sindical institucional", discorrem sobre os nexos entre o sindicalismo oriundo das greves operárias e populares desencadeadas a partir de fins da década de 1970 e as condições recentes de regulação do trabalho no Brasil, tendo como objeto a atuação sindical no Conselho de Relações de Trabalho (CRT), criado em 2010, verificando o que seriam as chances e limites da ação institucional do sindicalismo.

No texto "Trabalho e política em São Bernardo: arqueologia de uma hegemonia precária”, Ruy Braga tem como propósito refletir sobre as etnografias do trabalho operário e estudos de caso que, durante as décadas de 1970 e 1980, observaram as mudanças dos operários metalúrgicos de São Bernardo do 
Campo e o papel desempenhado por esses trabalhadores no processo de redemocratização no país. De um lado, discute as bases sociais do processo de inquietação operária no que diz respeito ao despotismo fabril e os limites à negociação como uma das razões das greves entre 1978 e 1981 e, de outro, analisa a relação social hegemônica que combinou o consentimento passivo das bases sociais com o consentimento ativo das lideranças sindicais na regulação dos conflitos sociais que vigorou no país entre os anos de 2003 e 2016.

Em diálogo com as diferentes abordagens da literatura sobre o tema, Alexandre Sampaio Ferraz, em "Quando os trabalhadores param? Reinterpretando a ocorrência de greves no Brasil”, analisa a incidência de greves nas diferentes fases econômicas e políticas do Brasil nas duas últimas décadas e discute essas paralisações no âmbito da conjuntura e dinâmica organizacional do movimento sindical. Nessa perspectiva, o estudo encontrou uma correspondência de menor volume de paralisações em governos de centro-direita quando comparado com governos de centro-esquerda e, de outra parte, à medida que aumenta a competição no interior do sindicalismo, tenderia a se elevar o número de greves.

Everton Lazzaretti Picolotto discorre, em "Pluralidade sindical no campo? Agricultores familiares e assalariados rurais em um cenário de disputas", sobre as principais questões relativas às mudanças na estrutura sindical dos trabalhadores rurais nas últimas décadas, marcadas pela emergência de novas identidades políticas que lutam pelo reconhecimento de sua diversidade e pela constituição de formas próprias de representação. Nesse aspecto, $o$ artigo analisa essas mudanças recentes na representação dos trabalhadores do campo, seus conflitos e as suas relações com o Estado, tendo como pano de fundo a criação de duas confederações: a primeira, representante dos agricultores familiares e, a segunda, dos assalariados rurais. 
O dossiê contempla, ainda, um conjunto de três textos sobre o sindicalismo internacional. No primeiro artigo, "Volviendo a las bases: el sindicalismo argentino frente a los retos del capitalismo actual”, Bruno Dobrusin e Juan Montes Cató abordam o sindicalismo na atual fase do desenvolvimento capitalista argentino e os desafios enfrentados pela ação sindical: o aprofundamento da flexibilidade, o crescimento dos mercados informais, o afastamento do Estado da regulação das relações entre capital e trabalho, e o aumento das empresas multinacionais como um setor que age em âmbito global. O estudo analisa também as implicações presentes nesse modelo e a resistência operária produzida a partir dos locais de trabalho.

Em "O sindicalismo ainda conta? Poderes sindicais em debate no contexto europeu", Hermes Augusto Costa analisa a relevância do sindicalismo a partir das mutações ocorridas ao longo da última década no contexto europeu. Assim, o estudo discute o legado histórico do sindicalismo e seu sentido plural ("as variedades de sindicalismo", traduzidas em teorias e modelos) para identificar as fontes de poder sindical. $\mathrm{O}$ argumento do autor é que, a despeito de vários aspectos de crise, o sindicalismo tem elementos de poder para ultrapassar suas fraquezas. Ao tratar de temas como representatividade, independência, ação internacional e construção de alianças sociais, o artigo chama atenção para o fato de que, tendo em vista a experiência europeia, esses elementos são menos fatores de crise e mais aspectos para a renovação sindical.

O texto de Davide Bubbico, "O sindicalismo italiano entre a crise de representatividade e mudanças das relações industriais", discute os impasses vividos pelo sindicalismo na Itália a partir dos anos 1980. O artigo tematiza a situação do sindicalismo confederal italiano demonstrando, a partir dos dados e da literatura sobre o tema, que esse sindicalismo vive, na atualidade, uma crise de representatividade cujas 
bases se devem à redução da taxa de sindicalização e à dificuldade de representar as novas formas de emprego produzidas pelos processos de reforma do mercado do trabalho nas últimas três décadas. O autor reflete sobre as novas formas de organização na representação dos trabalhadores precários e o maior dinamismo dos sindicatos de base extraconfederal na representação dos trabalhadores imigrantes como alguns dos aspectos que vêm contribuindo para a crise atual do sindicalismo italiano.

Por fim, o dossiê apresenta uma entrevista com Ruth Milkman, realizada por Marco Aurélio Santana, em que ela reflete sobre as classes trabalhadoras e a situação do trabalho nos Estados Unidos, bem como sobre os imensos desafios enfrentados pelo sindicalismo nesse país. Ao longo de suas formulações, Milkman analisa temas candentes e suas intersecções com o trabalho, a partir das questões ligadas à imigração, ao gênero, à raça e aos movimentos sociais, como aqueles levados a cabo pela chamada "geração milênio".

Este conjunto amplo e variado de contribuições, cobrindo os cenários nacional e internacional e incorporando diferentes tipos de teorias, métodos e fontes, pode auxiliar tanto o leitor especializado como o público em geral no entendimento de alguns dos processos que atravessam o mundo do trabalho e as formas de organização e mobilização da classe trabalhadora. Em um momento complexo como o atual, cujos fundamentos nem sempre restam claros à primeira vista, é sempre de grande valia poder contar com reflexões desse tipo.

Iram Jácome Rodrigues ${ }^{\mathrm{a}}$

aé professor do Departamento de Economia e do Programa de Pós-Graduação em Sociologia da Universidade de São Paulo (PPGS-USP).São Paulo, SP, Brasil. E-mail: <iramirodrigues@gmail.com> 


\section{Marco Aurélio Santana ${ }^{b}$}

bé professor do Departamento de Sociologia e do Programa de Pós-Graduação em Sociologia e Antropologia da Universidade Federal do Rio de Janeiro (PPGSA/IFCS-UFRJ). Rio de Janeiro, RJ, Brasil. E-mail: <marcosilvasantana@gmail.com>

Orcid: 0000-0002-3181-6964 http://dx.doi.org/10.1590/0102-0026/104

\section{REFERÊNCIAS}

GUMBRELL-MCCORMICK, Rebecca; HYMAN, Richard. 2013. Trade

Unions in Western Europe: hard times, hard choices. Oxford: Oxford

Universty Press.

RODRIGUES, Iram Jácome (org.). 1999. O novo sindicalismo: vinte anos depois. Petrópolis: Vozes.

2011. Sindicalismo e política: a trajetória da CUT (1983-1993). 2. ed.

São Paulo: LTr.

RODRIGUES, Iram Jácome; LIMA, Jacob Carlos; RAMALHO, José

Ricardo (orgs.). 2018. Sociedade, trabalho e sindicalismo na contemporaneidade. Tempo Social, v. 30, n. 1, pp. 1-178.

SANTANA, Marco Aurélio (org.). 2015. Para onde foram os sindicatos? Caderno $C R H$, v. 28, n. 75, pp. 453-567.

. As múltiplas dimensões do 68 operário no Brasil. In: BENJAMIN, Cid; DEMIER, Felipe (orgs.). 2018. Meio século de 1968: barricadas, história e política. Rio de Janeiro: Mauad. pp. 125-152. 